\title{
Metode Pemetaan Resistivitas Tanah pada Survei Pertanian dengan HUMA EC 1
}

\author{
Lumenta E.* dan Setiawan T. \\ Teknik Geofisika, Fakultas Teknik Pertambangan dan Perminyakan, Institut Teknologi Bandung, \\ Jalan Ganesa No 10, Bandung, 40132 \\ *Email: Ednerlumenta@gmail.com
}

Submit: 5 April 2017; Revised: 18 Mei 2017; Accepted: 20 Mei 2017

\begin{abstract}
Survey geofisika pertanian masih dapat dibilang baru dan parameter penting dari survei geofisika pertanian adalah sifat-sifat tanah (tekstur, struktur, porositas, resistivitas, dan lain-lain). Survei tanah dalam geofisika biasanya menggunakan metode resistivitas, induksi elektromagnetik (EMI), dan Ground Penetrating Radar (GPR) karena metode-metode ini cepat dan dapat memperkirakan banyak sifat- ifat tanah, seperti salinitas, konten batu, dan kedalaman air tanah, tetapi metode ini tidak dapat memberikan informasi tentang variasi properti tanah dalam suatu profil tanah. Array wenner adalah salah satu array yang sering digunakan untuk mengukur resistivitas semu tanah dangkal. Array wenner dapat dengan mudah menghitung resistivitas semu tanah di suatu daerah dan sensitivitas instrumen ini tidak sepenting dalam geometri array lain. Besaran arus yang relatif kecil diperlukan untuk mengukur perbedaan potensial. Kerugian array wenner adalah dalam setiap pengukuran, semua elektroda harus dipindahkan ke posisi baru. Secara umum instrumentasi metode resistivitas untuk pemetaan tanah menggunakan kabel karena instrument-instrumen ini dapat digunakan untuk berbagai array, HUMA EC 1 dirancang hanya untuk mengukur resistivitas tanah dangkal dan dengan HUMA EC 1 kita bisa mengukur sifat tanah dangkal dengan lebih cepat, mudah, dan murah. Dalam penelitian ini saya akan mengukur sifat-sifat tanah di daerah Kampung Padi dan di daerah Padaasih dengan OYO McOHM dan HUMA EC 1, dan mengkorelasikan hasil kedua data resistivitas tanah, sehingga kita akan tahu apakah daerah ini baik untuk pertanian.
\end{abstract}

Kata kunci: HUMA EC 1, konfigurasi wenner, OYO McOhm, pertanian, resistivitas.

\section{PENDAHULUAN}

Dalam bidang pertanian, metode geofisika yang umum digunakan dalam pengukuran adalah resistivitas, induksi elektromagnerik (EM), metode ground penetrating radar (GPR), metode self potensial (SP), seismik, dan metode magnetik (Allred dkk 2008, 2011, Nguyen dkk., 2017). Selain itu, teknologi penginderaan jauh juga digunakan untuk mengetahui salinitas tanah (Abbas dkk., 2013). Perkembangan aplikasi komputasi juga terjadi dalam bidang pertanian seperti penggunaan sensor pada tanah untuk mengetahui kelayakan masa tanam (Adamchuk dkk., 2004).

Salah satu metode geofisika yang akan digunakan dalam studi ini adalah metode resistivitas. Target dari geofisika pertanian difokuskan pada kedalaman yang dangkal untuk investigasi ketebalan tanah dan tingkat kesuburannya. Metode resistivitas mengukur resistivitas listrik, atau kebalikannyayaitu, konduktivitas listrik. Metode resistivitas pada dasarnya mengumpulkan data tentang medan listrik bawah permukaan yang dihasilkan oleh arus listrik buatan ke dalam tanah. Dengan metode resistivitas konvensional, arus listrik disuplai antara dua elektroda logam yang ditancapkan di permukaan tanah, sedangkan tegangan secara bersamaan diukur oleh pasangan elektroda logam yang terpisah yang ditancapkan di permukaan. Arus, tegangan, jarak antar elektroda, dan konfigurasi elektroda kemudian digunakan untuk menghitung nilai tahanan listrik tanah (atau konduktivitas).

Array dalam metode resistivitas ada bermacam-macam, namun dalam tugas akhir ini array yang akan digunakan adalah array wenner karena targetnya yang dangkal. Array wenner juga dapat dengan mudah menghitung resistivitas semu tanah di suatu daerah dan sensitivitas instrumen dalam array ini tidak terlalu penting dibandingkan dengan sensitivitas dalam array lain. Salah satu kelemahan yang dimiliki array wenner adalah dalam setiap pengukuran, semua elektroda harus dipindahkan ke posisi baru.

Secara umum instrumentasi metode resistivitas untuk pemetaan tanah menggunakan kabel karena instrumen ini dapat digunakan untuk berbagai pilihan array, karena itu dalam penelitian ini akan digunakan instrumen baru yang memang dirancang untuk mengukur resistivitas tanah dangkal. Instrumen ini juga dapat melakukan pengukuran sifat tanah dangkal dengan lebih mudah, lebih cepat, dan lebih murah.

\section{DATA DAN METODE}

Lokasi penelitian ladang jagung terletak di Kampung Padi, Dago, Bandung, Jawa Barat. Dago terletak tidak jauh dari lembang yang merupakan salah satu dari pusat industri agrikultur di Provinsi Jawa Barat karena iklim dan kesuburan tanahnya. 


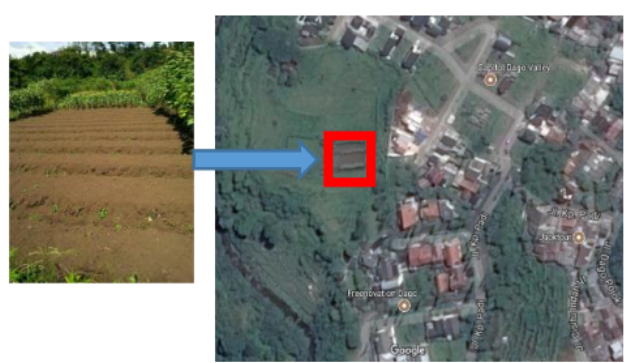

Gambar 1. Peta lokasi penelitian jagung. Sumber: Google Maps.

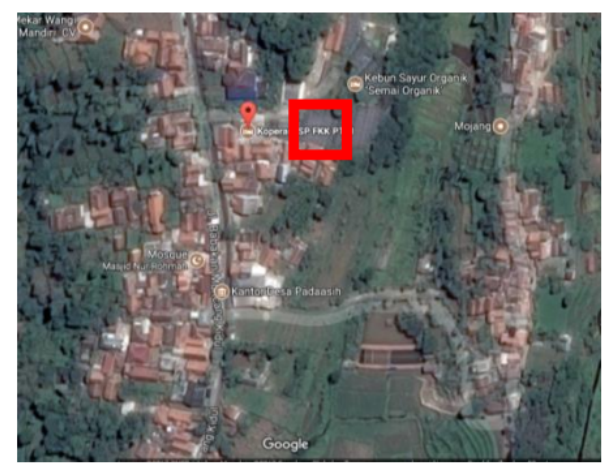

Gambar 2. Peta lokasi penelitian pak choi. Sumber:Google Maps.

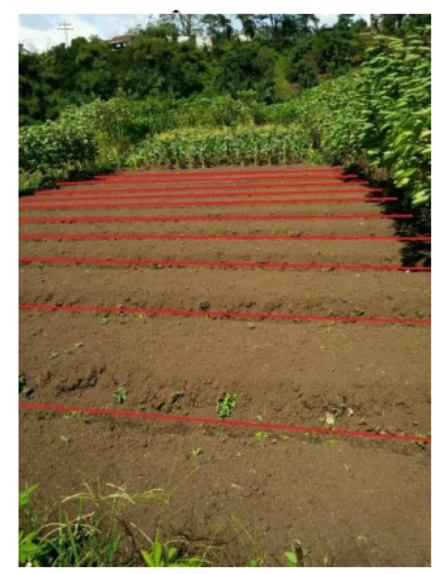

Gambar 3. Line pengukuran resistivitas ladang jagung.

Lokasi penelitian ladang pak choi terletak di Jl. Babakan Muncang Kidul No.61, Padaasih, Cisarua, Kabupaten Bandung Barat, Jawa Barat 40551, Indonesia. Ladang pak choi ini dikelola oleh Koperasi Keluarga Serikat Pekerja Forum Komunikasi Karyawan (SPFKK) PT DI.

Instrumen yang digunakan pada penelitian di ladang jagung ini adalah HUMA EC 1. Pengambilan data dilakukan pada tanggal 7 Februari 2017. Konfigurasi pengukuran yang digunakan adalah Wenner Array, dimana jarak antara elektrodannya adalah $40 \mathrm{~cm}$. Arus yang digunakan saat pengambilan data di lapangan adalah 2 Ampere.

Instrumen yang digunakan pada penelitian di ladang pak choi ini adalah HUMA EC 1 dan OYO McOhm.

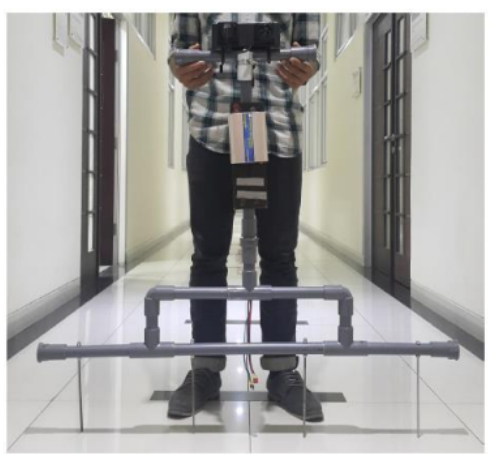

Gambar 4. Instrumen yang digunakan.

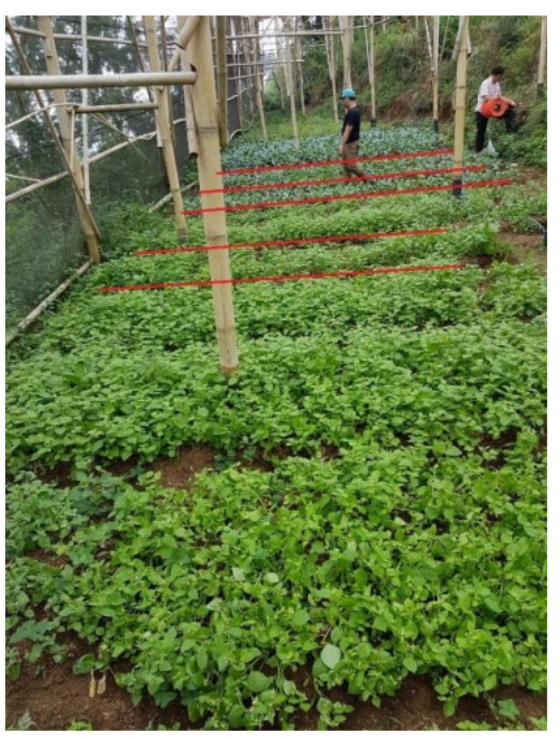

Gambar 5. Line pengukuran resistivitas ladang pak choi.

Pengambilan data dilakukan pada tanggal 19 Juli 2017. Konfigurasi pengukuran yang digunakan adalah Wenner Array, dimana jarak antara elektrodannya adalah $30 \mathrm{~cm}$. Arus yang digunakan saat pengambilan data di lapangan adalah 2 Ampere dengan stack 4. Pada ladang bekas pak choi putih dilakukan juga pengukuran dengan jarak antara elektrodannya adalah $30 \mathrm{~cm}$ dan $40 \mathrm{~cm}$.

\section{PENGOLAHAN DATA}

Nilai resistivitas didapat dengan mengolah data mentah dari kedua instrument dengan menggunakan software microsoft excel. Data yang didapatkan dari OYO McOhm adalah resistansi, data resistansi $(R)$ tersebut diolah menjadi resistivitas $(\rho)$ dengan rumus:

$$
\rho=R \times K
$$

Dimana $K$ adalah faktor geometri. Dalam konfigurasi wenner jarak antara masing-masing elektroda sama yaitu a, nilai $\mathrm{r} 1=\mathrm{r} 4=\mathrm{a}$, nilai $\mathrm{r} 2=\mathrm{r} 3=2 \mathrm{a}$, sehingga nilai $\mathrm{K}$ adalah:

$$
K=2 \pi a
$$

HUMA EC 1 masih belum dapat menampilkan nilai 


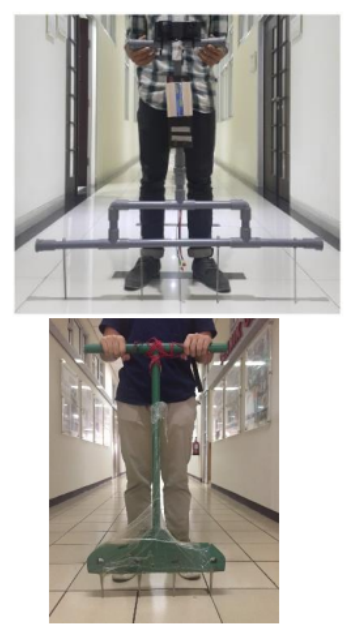

Gambar 6. Instrumen HUMA EC 1.

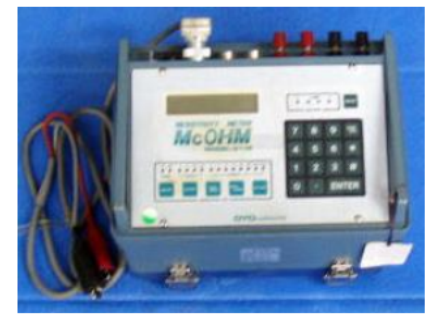

Gambar 7. Instrumen OYO McOhm.

resistansi secara langsung, sehingga perlu dilakukan pengolahan mandiri. Data yang di dapatkan dari HUMA EC 1 adalah self potential (SP), tegangan listrik (V), dan arus listrik (I). Dari ketiga data ini resistansi diperoleh dengan menggunakan rumus:

$$
R=\frac{v-\frac{s p}{1000}}{i}
$$

Sp dibagi 1000 karena sp dalam pengukuran masih dalam satuan milivolt, sehingga perlu dikonversi terlebih dahulu menjadi volt. Setelah mendapatkan nilai resistansi, perlu diolah lebih lanjut untuk mendapatkan nilai resistivitas dengan cara yang sama dengan OYO McOhm.

Setelah mendapatkan nilai resistivitas, selanjutnya dilakukan pemodelan 2-D dengan software surfer 9 untuk memetakan resistivitas listrik di lahan pengukuran. Oleh karena proses ini lebih mengarah ke interpretasi data, maka proses ini akan dijelaskan pada bab selanjutnya.

\section{HASIL DAN PEMBAHASAN}

\subsection{Lahan Jagung}

Berdasarkan hasil pemodelan 2-D dari data resistivitas di lahan jagung, didapatkan model resistivitas di kedalaman $40 \mathrm{~cm}$.

Gambar di atas, dapat dibagi menjadi 3 bagian, bagian warna biru, hijau, dan jingga. Warna jingga menandakan nilai resistivitas tinggi, warna hijau menandakan nilai resistivitas yang sedang, dan warna biru menandakan nilai resistiv-

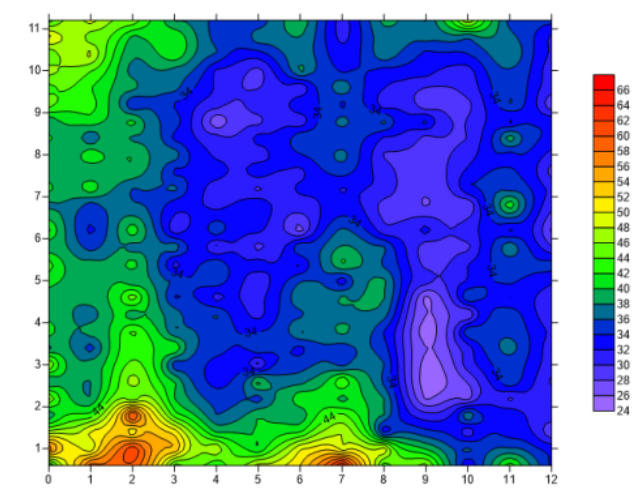

Gambar 8. Peta persebaran resistivitas lahan jagung.

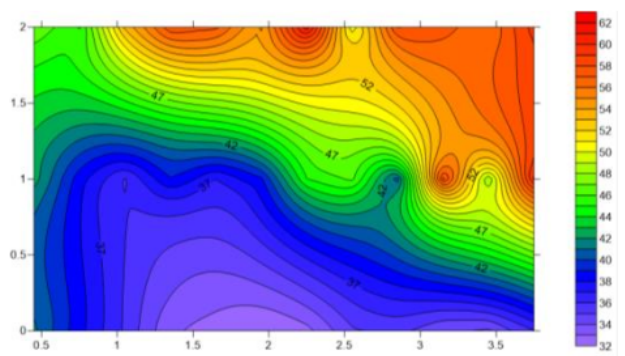

Gambar 9. Peta persebaran resistivitas lahan pak choi dengan OYO McOhm.

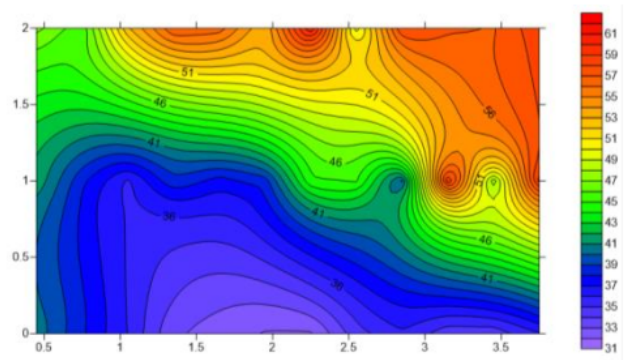

Gambar 10. Peta persebaran resistivitas lahan pak choi dengan HUMA EC 1.

itas yang rendah. Hal ini merupakan indikasi adanya perbedaan kadar air di beberapa titik pengukuran. Di daerah yang berwana biru banyak terdapat air, dan di daerah berwarna jingga kekurangan air. Perbedaan kadar air ini dapat memengaruhi pertumbuhan tanaman jagung. Jika tanaman jagung di tanam di daerah yang kadar airnya rendah, tanaman tersebut akan tumbuh lebih lama dibandingkan dengan tanaman jagung yang di tanam di daerah dengan kadar air tinggi. Namun belum diketahui kadar air yang optimal untuk tanaman jagung agar jagung dapat tumbuh dengan optimal (Corwin dkk., 2005).

\subsection{Lahan Pak Choi}

Berdasarkan hasil pemodelan 2-D dari data resistivitas di lahan pak choi, didapatkan model resistivitas dengan OYO McOhm dan dengan HUMA EC 1. 


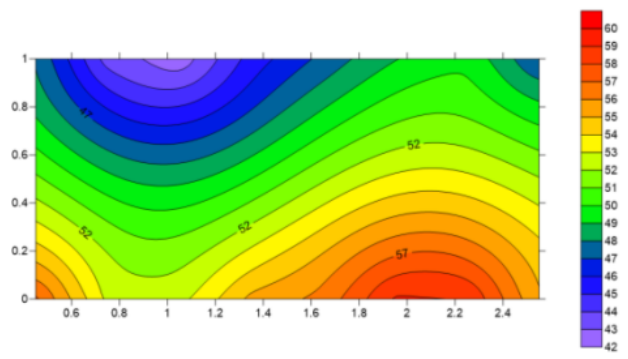

Gambar 11. Peta persebaran resistivitas lahan bekas pak choi putih dengan $\mathrm{OYO} \mathrm{McOhm}$ pada kedalaman $30 \mathrm{~cm}$.

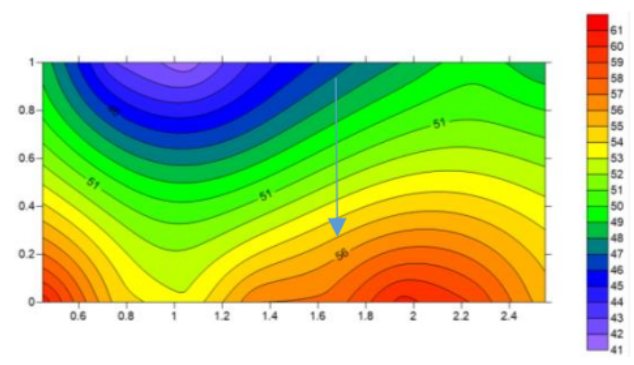

Gambar 12. Peta persebaran resistivitas lahan bekas pak choi putih dengan HUMA EC 1 pada kedalaman $30 \mathrm{~cm}$.

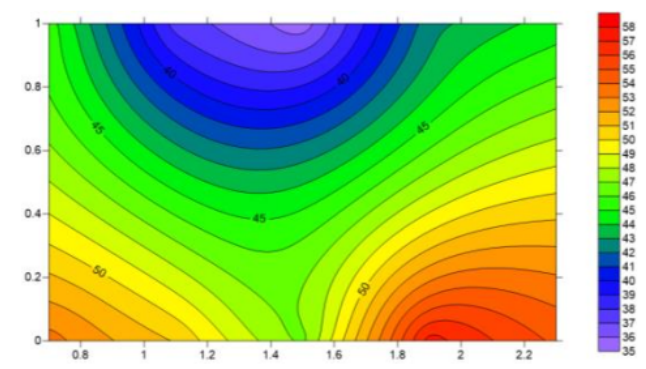

Gambar 13. Peta persebaran resistivitas lahan bekas pak choi putih dengan OYO McOhm pada kedalaman $40 \mathrm{~cm}$.

Kedua peta persebaran resistivitas lahan pak choi di atas menunjukan tren yang sama. Pada beberapa titik terdapat perbedaan nilai resistivitas, namun perbedaannya sangat kecil sehingga tidak terlalu berpengaruh terhadap hasil peta persebaran resistivitas. Seperti pada lahan jagung, daerah berwarna jingga merupakan daerah yang kekurangan air.

\subsection{Lahan Bekas Pak Choi Putih}

Berdasarkan hasil pemodelan 2-D dari data resistivitas di lahan bekas pak choi putih, didapatkan model resistivitas pada kedalaman $30 \mathrm{~cm}$ dengan OYO McOhm.

Kedua peta persebaran resisitivitas lahan bekas pak choi putih dengan instrumen OYO McOhm dan HUMA EC 1 pada kedalaman $30 \mathrm{~cm}$ menunjukkan tren yang sama.

Berdasarkan hasil pemodelan 2-D dari data resistivitas di lahan bekas pak choi putih, didapatkan model resistivitas pada kedalaman $40 \mathrm{~cm}$ dengan OYO McOhm, dengan HUMA EC 1.

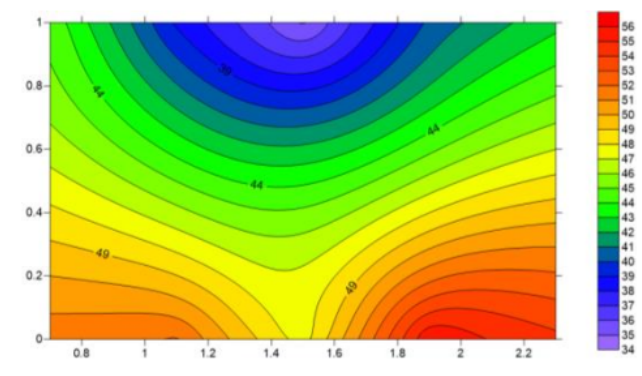

Gambar 14. Peta persebaran resistivitas lahan bekas pak choi putih dengan HUMA EC 1 pada kedalaman $40 \mathrm{~cm}$.

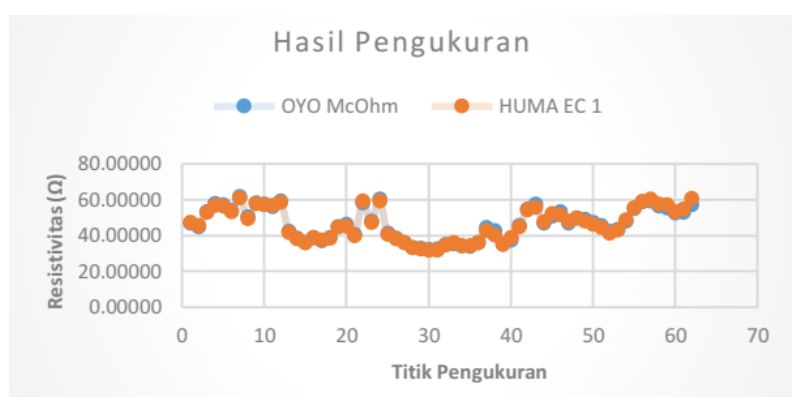

Gambar 15. Grafik pengukuran OYO McOhm dan HUMA EC 1.

Kedua peta persebaran resisitivitas lahan bekas pak choi putih dengan instrumen OYO McOhm dan HUMA EC 1 pada kedalaman $40 \mathrm{~cm}$ menunjukkan tren yang sama. Kedua peta persebaran resisitivitas lahan bekas pak choi putih pada kedalaman $30 \mathrm{~cm}$ dan $40 \mathrm{~cm}$ menunjukan tren resistivitas yang serupa tapi sedikit berbeda (McCauley dkk., 2005). Hal ini merupakan indikasi dari arah aliran air yang semakin ke dalam semakin bergerak ke timur.

\subsection{Perbandingan Resistansi OYO McOhm dan HUMA EC 1}

Dari data pengukuran resistansi di lapangan yang di ambil dengan instrumen OYO McOhm dan HUMA EC 1, kemudian hubungan keduanya dilihat perbedaannya dengan menggunakan grafik dan korelasi. Gambar 15 menunjukkan grafik hubungan kedua data resistansi antara OYO McOhm dan HUMA EC 1 yang diukur di lapangan.

Berdasarkan grafik di atas, terdapat pola yang sama antara garis biru (OYO McOhm) dengan garis jingga (HUMA EC 1). Nilai korelasi antara keduanya sebesar 0.99430. Hal ini menunjukkan bahwa instrumen HUMA EC 1 menghasilkan kualitas data yang sama dengan OYO McOhm.

\section{KESIMPULAN}

Dari penelitian ini dapat disimpulkan bahwa:

(i) Hasil pengukuran dengan instrumen HUMA EC 1 dan OYO McOhm menghasilkan tren resistansi yang sama, ini menandakan HUMA EC 1 sudah dapat digunakan di lapangan pertanian yang sebenarnya. 
(ii) Hasil pengukuran nilai resistivitas pada kedalaman 30 $\mathrm{cm}$ dan $40 \mathrm{~cm}$, memiliki tren yang serupa namun terdapat perbedaan, ini dikarenakan arah aliran air yang bergerak mengikuti pori-pori dalam tanah.

(iii) Dengan melakukan pengukuran metode tahanan jenis (resistivitas) di lahan pertanian, dapat diketahui persebaran daerah yang kadar airnya terlalu tinggi atau terlalu rendah, namun karena belum adanya nilai acuan untuk kadar air yang optimal untuk masing- asing tanaman, belum dapat diketahui daerah mana yang terlalu tinggi kadar airnya.

\section{REFERENCES}

Abbas, A., Khan, S., Hussain, N., Hanjra, M.A., Akbar, S. (2013): Characterizing Soil Salinity in Irrigated Agriculture using a Remote Sensing Approach. Journal on Physics and Chemistry of the Earth

Adamchuk, V.I., Hummel, J.W., Morgan, M.T., Upadhyaya, S.K. (2004): On-the-go Soil Sensors for Precision Agriculture. Journal on Computer and Electronics in Agriculture

Allred, B.J., Daniels, J.J., Ehsain, M.R. (2008): Handbook Agricultural Geophysics. CRC Press.USA

Allred, B.J. (2011): Agricultural Geophysics: Past/Present Accomplishments and Future Advancements. The Second Global Workshop on Proximal Soil Sensing-Montreal 2011

Corwin, D.L., Lesch S.M. (2005): Apparent soil electrical conductivity measurements in agriculture. Journal on Computers and Electronics in Agriculture

McCauley, A., Jones, C., Jacobsen, J. (2005): Basic Soil Properties. Montana State University Extension Service

Nguyen, A.Q, Klysz, G., Deby, F. (2017): Evaluation of water content gradient using a new configuration of linear array fourpoint probe for electrical resistivity measurement. Journal of Cement and Concrete Composites. 